\title{
Effect of hydrogen on fatigue crack growth of quenched and tempered CrMo(V) steels
}

\author{
Luis Borja Peral ${ }^{1, *}$, Sergio Blasón ${ }^{1}$, Alfredo Zafra ${ }^{1}$, Cristina Rodríguez $^{1}$, and Javier Belzunce ${ }^{1}$ \\ ${ }^{1}$ Polytechnic Engineering School, University of Oviedo, campus universitario, 33203 Gijón, Spain
}

\begin{abstract}
In order to select the most appropriate steel to deal with pressurized hydrogen during long times, the fatigue crack propagation rate of quenched and tempered $2.25 \mathrm{Cr} 1 \mathrm{Mo}$ and $2.25 \mathrm{Cr} 1 \mathrm{Mo} 0.3 \mathrm{~V}$ steel grades was evaluated by means of tests performed on thermally pre-charged specimens in a hydrogen reactor at 195 bar and $450^{\circ} \mathrm{C}$ during 21 hours. Cylindrical samples to measure the hydrogen content and their desorption kinetics at room temperature and compact tensile specimens to determine the fatigue crack growth rate were used. Finally, scanning electronic microscopy was used in the study of fracture surfaces. Using the aforementioned pre-charging conditions, significant amounts of hydrogen were introduced, being much larger in the $2.25 \mathrm{Cr} 1 \mathrm{Mo} 0.3 \mathrm{~V}$ steel grade (vanadium carbides provide strong hydrogen tramps). Regarding fatigue tests, the fatigue crack growth rate was increased notably due to the presence of hydrogen in the $2.25 \mathrm{Cr} 1 \mathrm{Mo}$ grades for frequencies lower than $10 \mathrm{~Hz}$. On the other hand, the presence of vanadium carbides has significantly improved the fatigue crack propagation performance in the presence of internal hydrogen.
\end{abstract}

\section{Introduction}

Vessels used to store and transport hydrogen must be able to provide a safe service during long periods of time in direct contact with gaseous hydrogen under high internal pressure, being so essential to ensure good resistance to hydrogen embrittlement. Generally, quenched and tempered steels alloyed with chrome, chrome-molybdenum or chrome-molybdenumvanadium are used in these industrial installations. Nevertheless, in order to reduce the vessel wall thickness, high yield strength steels are preferred, although it is well known that these steels are more sensitive to hydrogen embrittlement [1]. This type of components, which are also subjected to important cyclic loads, are used to work under high pressures of hydrogen (up to $100 \mathrm{MPa}$ ) and hydrogen absorption and diffusion into the steel microstructure might take place during the working period. The combination of all these factors, acting simultaneously, might give rise to hydrogen embrittlement processes, therefore decreasing the mechanical properties of these steel grades. For this reason, it is important to know, how hydrogen diffuses and accumulates in the process zone existing ahead of any existent defect until reaching a critical concentration which could trigger the failure of the component. One important task for material scientists and engineers is the development of materials and systems able to withstanding the effects of cyclic loading in hydrogen environments. Complete and detailed studies quantifying the influence of hydrogen on fatigue crack growth rate are still scarce, as most studies have mainly examined the influence of hydrogen on tensile properties. Nevertheless, in order to produce components able to perform satisfactorily in services for up to 15 years under high hydrogen pressures, it is an urgent need to produce reliable data on the fatigue behaviour of candidate materials in hydrogen environments [2-3].

In order to simulate the interaction between hydrogen atoms and the steel microstructure, there are two basic ways to analyse the effects of hydrogen in the mechanical properties of the steels: testing in highpressure hydrogen gas (external hydrogen) and testing in air after pre-charging the specimens in a hydrogenated medium (internal hydrogen). In this second case, specimens can be pre-charged at high temperature from a gaseous atmosphere or electrochemically from an aqueous solution at room temperature. In this work, pre-charging gaseous hydrogen at high temperature was used. In this way, given the exponential variation of the diffusion coefficient and solubility with temperature, the kinetics of hydrogen entry into the steel can be significantly accelerated and, after a few hours, a similar concentration of hydrogen to that obtained after years of service at room temperature can be reached.

*Corresponding author: luisborjapm@gmail.com 
Nevertheless, the largest drawback of this technique is the necessity to carry out the mechanical tests just after the hydrogen pre-charge in order to limit their desorption.

Compact specimens of quenched and tempered CrMo and $\mathrm{CrMoV}$ steels were thermally pre-charged and fatigue crack propagation rates were determined in this work. The influence of frequency on fatigue crack growth rate was also studied. Finally, scanning electronic microscopy (SEM) was used to analyse failure micromechanisms.

\section{Experimental procedure}

\subsection{Materials and heat treatments}

Two different low-alloyed ferritic steels from the Cr-Mo family have been selected in this study, with and without vanadium. The chemical composition of $2.25 \mathrm{Cr} 1 \mathrm{Mo}$ and $2.25 \mathrm{Cr} 1 \mathrm{Mo} 0.3 \mathrm{~V}$ steels is shown in Table 1.

Table 1. Chemical composition (weight \%).

\begin{tabular}{|c|c|c|c|c|c|c|}
\hline Steel & $\mathrm{C}$ & $\mathrm{Mn}$ & $\mathrm{Si}$ & $\mathrm{Cr}$ & $\mathrm{Mo}$ & $\mathrm{V}$ \\
\hline $2.25 \mathrm{Cr} 1 \mathrm{Mo}$ & 0.14 & 0.56 & 0.16 & 2.23 & 1 & - \\
\hline $2.25 \mathrm{Cr} 1 \mathrm{Mo} 0.3 \mathrm{~V}$ & 0.15 & 0.52 & 0.09 & 2.27 & 1 & 0.3 \\
\hline
\end{tabular}

2.25Cr1Mo and $2.25 \mathrm{Cr} 1 \mathrm{Mo} 0.3 \mathrm{~V}$ steels were studied in the as-received (AR) condition (see Table 2). In addition, $2.25 \mathrm{Cr} 1 \mathrm{Mo}$ steel was austenitized at $940^{\circ} \mathrm{C}$ for $30 \mathrm{~min}$, quenched in water and tempered at $600^{\circ} \mathrm{C}$ for two hours. In this way, due to the applied heat treatment, two steel grades with the same chemical composition were obtained in the case of the $2.25 \mathrm{Cr} 1 \mathrm{Mo}$ steel. The sequence of heat treatments and the nomenclature of all the studied grades (based on the tempering temperature) are shown in Table 2.

Table 2. Applied heat treatments.

\begin{tabular}{|c|c|}
\hline Steel grade & Heat treatment sequences \\
\hline 2.25Cr1Mo_690 & $\begin{array}{c}\mathrm{AR}: 940^{\circ} \mathrm{C} / 3 \mathrm{~h}+\text { water quench } \\
+690^{\circ} \mathrm{C} / 30 \mathrm{~h} \text { tempered }\end{array}$ \\
\hline 2.25Cr1Mo_600 & $\begin{array}{c}940^{\circ} \mathrm{C} / 30 \mathrm{~min}+\text { water } \\
\text { quench }+600^{\circ} \mathrm{C} / 2 \mathrm{~h} \text { tempered }\end{array}$ \\
\hline 2.25Cr1Mo0.3V_650 & $\begin{array}{c}\mathrm{AR}: 925^{\circ} \mathrm{C} / 90 \mathrm{~min}+\text { water } \\
\text { quench }+650^{\circ} \mathrm{C} / 2 \mathrm{~h} \text { tempered }\end{array}$ \\
\hline
\end{tabular}

Different specimens were machined to perform the different tests: small cylindrical samples to measure hydrogen contents and the kinetics of hydrogen egression at room temperature (RT) and also compact tensile specimen for fatigue crack growth rate determination.

\subsection{Hydrogen pre-charging}

All the specimens were pre-charged with gaseous hydrogen in a high-pressure hydrogen reactor. In order to make sure that the specimens were saturated with hydrogen, the following conditions were applied: 21 hours at $450^{\circ} \mathrm{C}$ under a pressure of $19.5 \mathrm{MPa}$ of pure hydrogen. After this maintenance time, a cooling phase of $1 \mathrm{~h}$, until attaining a temperature of $85^{\circ} \mathrm{C}$ (keeping the hydrogen pressure at $19.5 \mathrm{MPa}$ to minimize hydrogen egress) was always used. Afterwards, the hydrogen precharged specimens were removed from the reactor and rapidly immersed in liquid nitrogen $\left(-196^{\circ} \mathrm{C}\right)$, where they were kept until the moment of testing, in order to avoid hydrogen loss.

\subsection{Measurement of hydrogen content}

The amount of hydrogen absorbed in the different steel grades and the hydrogen desorption curves at room temperature were determined. With this purpose, cylindrical samples with a diameter of $10 \mathrm{~mm}$ and a length of $30 \mathrm{~mm}$ were used $(\approx 20 \mathrm{~g})$.

The hydrogen content was measured in a LECO DH603 analyzer, which is able to measure hydrogen concentrations between 0.1 and 2500 ppm. The measuring principle of the equipment is based on the difference of thermal conductivity between a reference gas flow of pure nitrogen and a secondary flow carrying nitrogen and the hydrogen thermally extracted from the specimen. This conductivity difference is measured by means of a Wheatstone bridge and converted into an electrical signal that is interpreted by the equipment software, which finally gives the sample hydrogen concentration in "ppm".

The procedure to obtain the desorption curves was the following: all the samples were removed from the liquid nitrogen at the same time, and exposed in air at room temperature. Then, the hydrogen concentration of the samples was measured at different time intervals. Before starting the measure, each sample was cleaned in an ultrasonic bath with acetone for 5 minutes, and then carefully dried using cold air. The analysis to determine hydrogen concentration consists on keeping the sample at $1100^{\circ} \mathrm{C}$ during approximately 400 seconds in the aforementioned LECO DH603 analyzer.

\subsection{Fatigue crack growth tests}

Fatigue crack growth rate determination was performed using compact tensile, $\mathrm{CT}$, specimens, with a width of 48 $\mathrm{mm}$ and a thickness of $10 \mathrm{~mm}$ (see Figure 1). The specimens were always fatigue pre-cracked before precharging to obtain an initial crack length versus width ratio, $\mathrm{a} / \mathrm{W}=0.2$, using an $\mathrm{R}$ ratio of 0.1 and following the ASTM E647 standard [4]. The initial applied $\Delta \mathrm{K}$ was about $35 M P a \cdot \sqrt{m}$, and always a $\mathrm{R}$ ratio of 0.1 was used in these tests performed at RT. Crack length was continuously monitored with the aid of a CTOD extensometer and a nominal frequency of $10 \mathrm{~Hz}$ was employed. Moreover, in the case of the hydrogen precharged specimens, frequencies of 1 and $0.1 \mathrm{~Hz}$ were also used in order to evaluate the influence of this parameter in HE. The curves representing crack growth rate $(\mathrm{da} / \mathrm{dN})$ versus stress intensity factor range $(\Delta \mathrm{K})$ of uncharged and hydrogen pre-charged specimens were subsequently compared. 


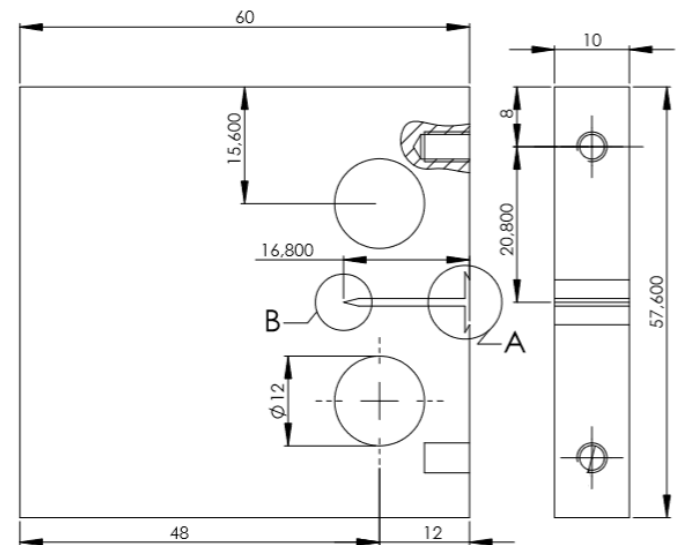

Fig. 1. Geometry and dimensions $(\mathrm{mm})$ of CT specimens.

\subsection{Observation of microstructures and fracture surfaces}

The steel microstructures were observed in a scanning electron microscope (SEM JEOL-JSM5600) using an acceleration voltage of $20 \mathrm{kV}$ (the samples were previously ground and finally polished with diamond paste of $1 \mu \mathrm{m}$ and etched with Nital). The fracture surfaces of the tested specimens were also carefully examined using the same technique.

\section{Results}

\subsection{Microstructure}

The resultant microstructures of $2.25 \mathrm{Cr} 1 \mathrm{Mo}$ and $2.25 \mathrm{Cr} 1 \mathrm{Mo} 0.3 \mathrm{~V}$ steels after the heat treatments described in Table 2 are shown in Figure 2.
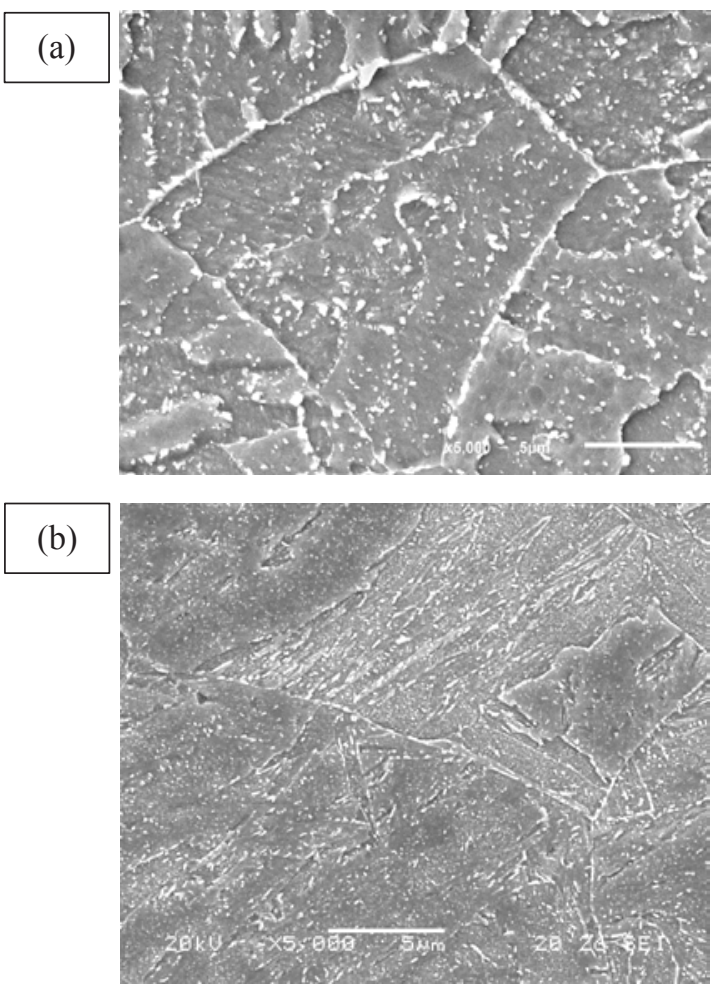

(c)

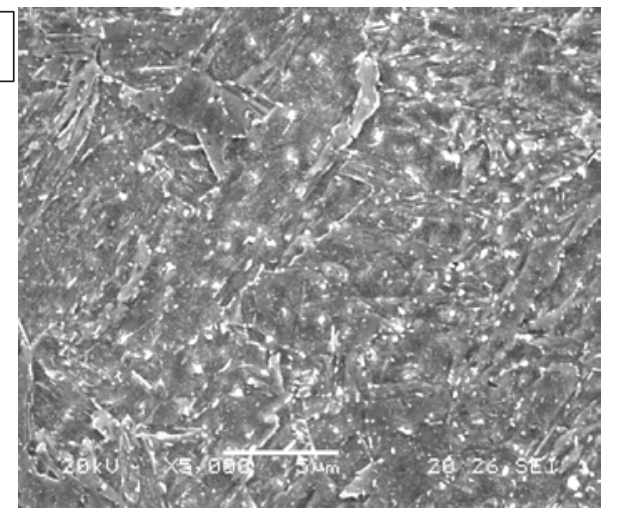

Fig. 2. Microstructure of heat treated steels (x5000). 2.25Cr1Mo_690 (a). 2.25Cr1Mo_600 (b) and $2 . \overline{2} 5 \mathrm{Cr} 1 \mathrm{Mo} 0.3 \mathrm{~V} \_650(\overline{\mathrm{c}})$.

All these microstructures correspond to tempered martensite. Microstructural differences between the steels and heat treatments are also noticed in the hardness (Brinell hardness) and tensile properties shown in Table 3. $\sigma_{\mathrm{y}}$ is the yield strength; $\sigma_{\mathrm{u}}$, the ultimate tensile strength; and e the total elongation.

Table 3. Hardness and tensile properties of the different steel grades.

\begin{tabular}{|c|c|c|c|c|}
\hline Grado de acero & HB & $\begin{array}{c}\sigma_{\mathrm{y}} \\
(\mathrm{MPa})\end{array}$ & $\begin{array}{c}\sigma_{\mathrm{u}} \\
(\mathrm{MPa})\end{array}$ & $\begin{array}{c}\mathrm{e} \\
(\%)\end{array}$ \\
\hline CrMo_690 & 170 & 430 & 580 & 27 \\
\hline CrMo_600 & 285 & 761 & 887 & 19.5 \\
\hline CrMoV_650 & 262 & 667 & 829 & 20 \\
\hline
\end{tabular}

\subsection{Hydrogen pre-charging}

Hydrogen solubility in ferritic steels at high temperature, considering that traps are not active at these temperatures, as reported by Pillot [5], can be calculated using Equations (1) for CrMo steels and (2) for CrMoV steel grades.

$$
\begin{aligned}
& C_{H}=0.152 \cdot \exp (-27079 / R \cdot T) \cdot \sqrt{P} \\
& C_{H}=9.23 \cdot 10^{-3} \cdot \exp (-6943 / R \cdot T) \cdot \sqrt{P}
\end{aligned}
$$

Where $C_{H}$ represents the hydrogen content expressed in 'mass ppm', $\mathrm{R}$ is the gas constant $(8.31 \mathrm{~J} / \mathrm{mol} \cdot \mathrm{K}), \mathrm{T}$ is the temperature $(\mathrm{K})$ and $\mathrm{P}$ the hydrogen pressure $(\mathrm{Pa})$. Applying these equations to our charging conditions, hydrogen contents of 7.5 and 13 ppm were respectively introduced into the CrMo and $\mathrm{CrMoV}$ steel samples. It may be mentioned that significant hydrogen loss takes place in the course of the cooling phase (1 hour) until reaching the reactor sample extraction temperature of $85^{\circ} \mathrm{C}$.

\subsection{Hydrogen desorption curves}

The hydrogen desorption curves obtained at room temperature with each steel grade are shown in Figure 3. These figures represent the hydrogen content evolution 
(ppm) versus the exposure time in air (hours) at room temperature. The initial hydrogen content, $\mathrm{C}_{\mathrm{H} 0}$, corresponds to the first point of the desorption curve (hydrogen content at the end of the cooling phase following thermal pre-charge). The residual hydrogen, $\mathrm{C}_{\mathrm{Hf}}$, is the hydrogen strongly trapped in the steel microstructure, hydrogen content after a long exposure at room temperature, being the diffusible hydrogen, the amount that is able to get out from traps and diffuse out of the steel when enough time is available, the difference between these two values $\left(\mathrm{C}_{\mathrm{H} 0}-\mathrm{C}_{\mathrm{Hf}}\right)$.
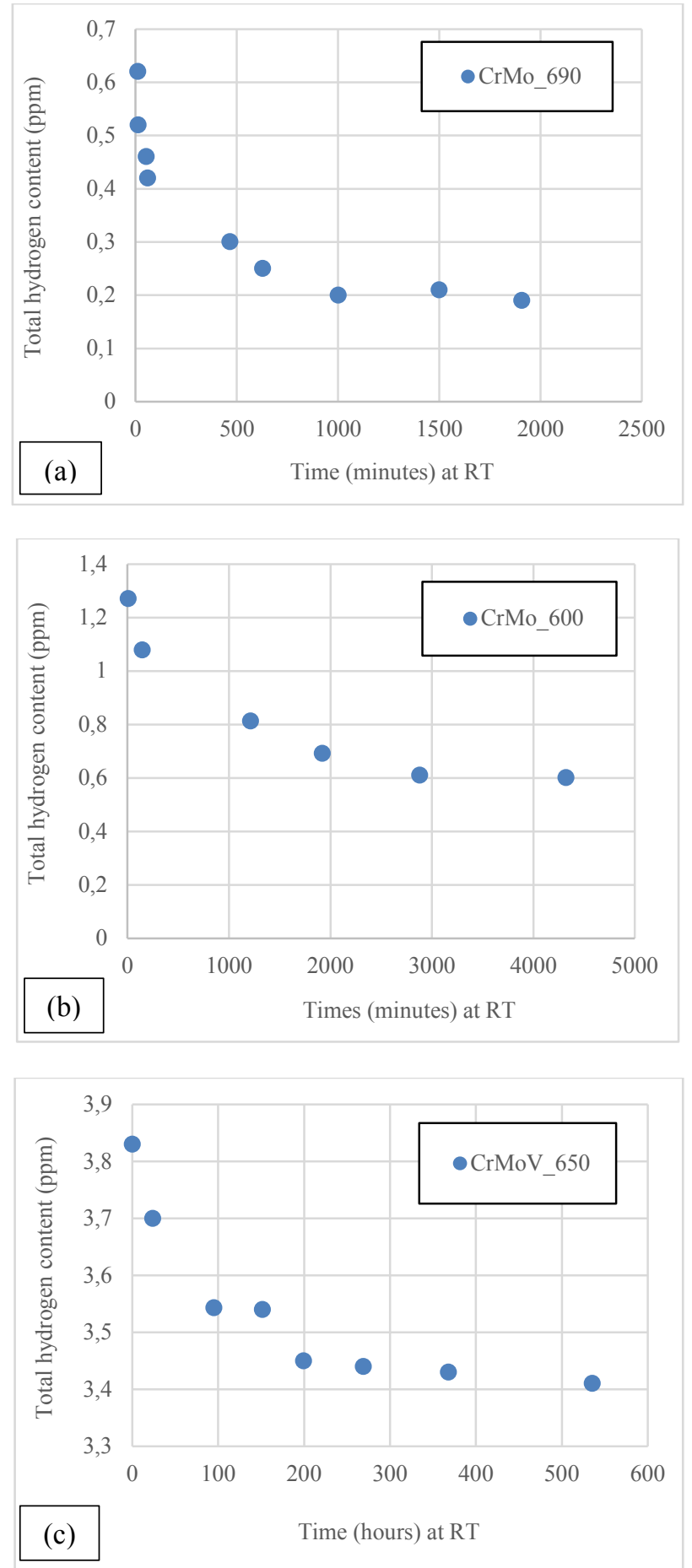

Fig. 3. Hydrogen desorption curves. CrMo_690 (a) CrMo_600 (b) and CrMoV_650 (c).
In line with the heat treatments previously applied and regarding the $2.25 \mathrm{Cr} 1 \mathrm{Mo}$ steel, when the tempering temperature increases, the initial and residual hydrogen contents decrease, as this microstructure has lower density of traps and strong traps. 2.25Cr1Mo steels always desorbed hydrogen much faster than $\mathrm{V}$-added steel, despite having less initial content (0.60-1.30 ppm respectively) than the vanadium steel $(3.80 \mathrm{ppm})$. For example, all diffusible hydrogen diffused out from the $\mathrm{V}$-free steels in about twenty-four hours but only $3 \%$ diffused out from $0.3 \mathrm{~V}$ after the same time. It was previously demonstrated that fine precipitated $\mathrm{V}$ carbides are very strong hydrogen traps $[5,6]$ and this explains the high values of initial and residual hydrogen contents measured in this steel grade. Table 4 shows the results obtained with the three steel grades.

Table 4. Initial $\left(\mathrm{C}_{\mathrm{H} 0}\right)$, residual $\left(\mathrm{C}_{\mathrm{Hf}}\right)$ and diffusible $\left(\mathrm{C}_{\mathrm{H}^{-}}\right.$ $\left.\mathrm{C}_{\mathrm{Hf}}\right)$ hydrogen contents measured in the different steel grades.

\begin{tabular}{|c|c|c|c|c|}
\hline \multirow{2}{*}{ Grade of steel } & $\mathrm{C}_{\mathrm{H} 0}$ & $\mathrm{C}_{\mathrm{Hf}}$ & \multicolumn{2}{|c|}{$\mathrm{C}_{\mathrm{H} 0}-\mathrm{C}_{\mathrm{Hf}}$} \\
\cline { 4 - 5 } & {$[\mathrm{ppm}]$} & {$[\mathrm{ppm}]$} & $\mathrm{ppm}$ & $\%$ \\
\hline 2.25Cr1Mo_690 & 0.60 & 0.20 & 0.40 & 67 \\
\hline 2.25Cr1Mo_600 & 1.30 & 0.60 & 0.70 & 54 \\
\hline 2.25Cr1Mo0.3V_650 & 3.80 & 3.40 & 0.40 & 10 \\
\hline
\end{tabular}

\subsection{Hydrogen diffusion coefficient estimation}

Data adjustment of the experimentally measured hydrogen desorption curves was used to estimate the apparent hydrogen diffusion coefficient of the three steel grades. We performed an axysimetric bi-dimensional diffusion analysis for the cylindrical samples using a commercial FEM software (Abaqus Cae). The hydrogen initial distribution, after the cooling phase (from 450 to $85^{\circ} \mathrm{C}$ performed in the high pressure reactor) for the CrMo 690 steel is shown in Figure 4. This hydrogen distribution corresponds to the first point of the desorption curve in Fig. 3 (a), where an average hydrogen content of $0.6 \mathrm{ppm}$ was experimentally measured, although the specimen surface has the residual hydrogen content $(0.2 \mathrm{ppm})$ and hydrogen contents as high as $0.9 \mathrm{ppm}$ are still present in the centre of the specimen. This hydrogen distribution was taken as the first point (boundary condition) to analyse the desorption curve of Fig. 3(a).

The Fick diffusion law $\left(\mathrm{J}=-\mathrm{D}_{\text {app }} \nabla \mathrm{C}_{\mathrm{L}}\right.$, being $\mathrm{J}$ the hydrogen flux, $\mathrm{D}_{\text {app }}$ the apparent diffusion coefficient, and $\mathrm{C}_{\mathrm{L}}$ represents the lattice hydrogen concentration) was applied to a cylinder with a radius of $5 \mathrm{~mm}$ using the apparent diffusion coefficient, $\mathrm{D}_{\mathrm{app}}$, as variable and the hydrogen evolution with time at RT was calculated. The diffusion coefficient which better adjusted the experimental data was taken as the apparent diffusion coefficient of the steel. The $\mathrm{D}_{\text {app }}$ value estimated for the CrMo_690 steel grade was $2.4 \cdot 10^{-9} \mathrm{~m}^{2} / \mathrm{s}$ and the adjustment to the experimental data is shown in Figure 5. 
Table 5 shows the apparent diffusion coefficient calculated on the three steel grades. As tempering temperature of the CrMo steel increases, the diffusion coefficient significantly increases, although the variation of the diffusion coefficient is even greater for the $\mathrm{CrMoV}$ steel, which has a relatively very low hydrogen diffusion coefficient.

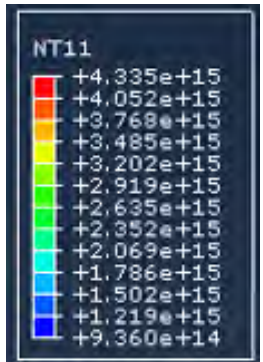

$\left(\mathrm{H}\right.$ atoms $\left./ \mathrm{mm}^{3}\right)$

CAX8RT element type

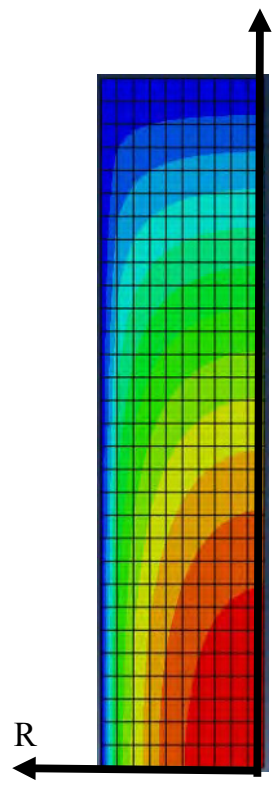

Fig. 4. Hydrogen initial distribution in the CrMo_690 steel $\left(\mathrm{C}_{\mathrm{H}}=0.6 \mathrm{ppm}\right)$ with $\mathrm{R}=5 \mathrm{~mm}$ and $\mathrm{L}=30 \mathrm{~mm}$.

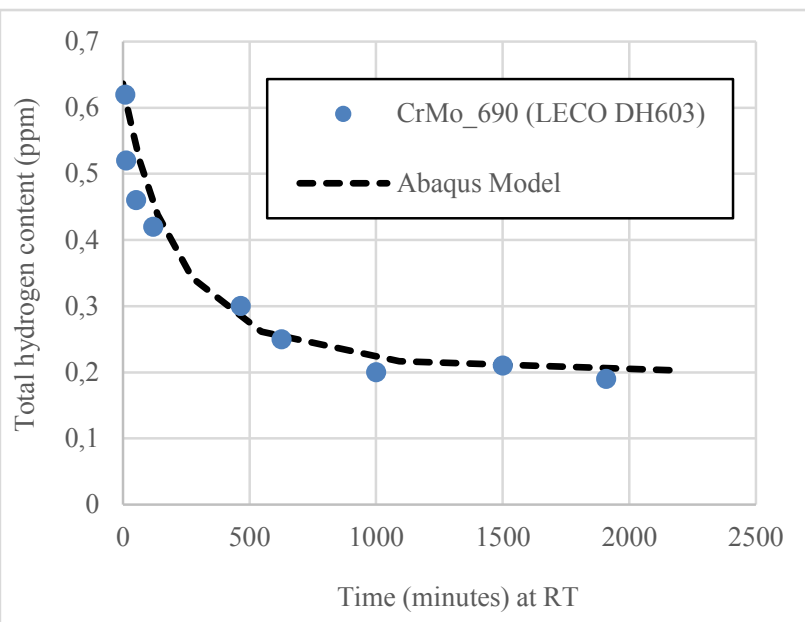

Fig. 5. CrMo_690 grade of steel. Adjustment of the apparent diffusion coefficient.

The apparent hydrogen diffusion coefficients of the three studied steels are shown in Table 5.

Table 5. Hydrogen diffusion coefficients ( $\left.D_{\text {app }}\right)$.

\begin{tabular}{|c|c|c|c|}
\hline Grade of steel & $\begin{array}{c}\mathrm{C}_{\mathrm{H} 0} \\
{[\mathrm{ppm}]}\end{array}$ & $\begin{array}{c}\mathrm{C}_{\mathrm{Hf}} \\
{[\mathrm{ppm}]}\end{array}$ & $\begin{array}{c}\mathrm{D}_{\text {app }} \\
{\left[\mathrm{m}^{2} / \mathrm{s}\right]}\end{array}$ \\
\hline 2.25Cr1Mo_690 & 0.60 & 0.20 & $2.4 \cdot 10^{-9}$ \\
\hline 2.25Cr1Mo_600 & 1.30 & 0.60 & $8.0 \cdot 10^{-10}$ \\
\hline 2.25 Cr1Mo0.3V_650 & 3.80 & 3.40 & $8.010^{-11}$ \\
\hline
\end{tabular}

The hydrogen diffusion coefficient measured in V-added steel was one or two orders of magnitude lower than that obtained in the V-free steels (depending on tempering temperature). This result corroborates previous ones, in which vanadium carbides were seen to be very strong hydrogen microstructural traps $[5,6]$.

\subsection{Fatigue crack growth curves}

The curves representing the fatigue crack growth rate $(\mathrm{da} / \mathrm{dN}) \mathrm{vs}$ the stress intensity factor range $(\Delta \mathrm{K})$ obtained with the three steel grades are shown as a function of the test frequency in Figure 6. The acceleration effect in the fatigue crack growth rate was only noted when the test frequency was lower than $10 \mathrm{~Hz}$ and this effect was more important under the lowest test frequency $(0.1 \mathrm{~Hz})$, as it would be expected according to previous works $[2,3,7]$.

On the other hand, the ratio between hydrogen crack growth rate $(\mathrm{da} / \mathrm{dN})_{\mathrm{H}}$ measured with hydrogen precharged specimens under the lowest frequency $(0.1 \mathrm{~Hz})$ and the crack growth rate obtained with uncharged specimens $(\mathrm{da} / \mathrm{dN})_{\mathrm{NoH}}$ was plotted as a function of the applied $\Delta \mathrm{K}$ in Figure 7. This factor is an indicator of the hydrogen embrittlement susceptibility under cyclic loads. It is worth to note that the aforementioned acceleration ratio is the largest for low $\Delta \mathrm{K}$ values and frequencies. For the other hand, crack growth acceleration under internal hydrogen was much lower in the V-added steel, although the internal hydrogen present in this steel was the largest.

\subsection{Fracture surfaces}

The fracture surfaces of the fatigued CT specimens were analysed under the scanning electron microscope. As mentioned above, the most relevant differences were noted at the lowest test frequencies $(0.1 \mathrm{~Hz})$ and for the lowest $\Delta \mathrm{K}$ values. Fig. $8 \mathrm{a}$ shows the fatigue surface of the uncharged CrMo_690 steel grade (the most hydrogen embrittled grade under cyclic loads), where typical fatigue striations are clearly seen. On the contrary, in the fatigue surface of the hydrogen pre-charged specimens tested at $0.1 \mathrm{~Hz}$, striations dissapeared and PRHIC (plasticity related hydrogen induced cracking) micromechanisms (white circles, Fig. 8b) with some small areas of brittle intergranular (IG) fractures (white arrows, Fig. 8b) are visible [8]. In this case, hydrogen accumulation in front of the crack, where the hydrostatic stress attains a maximum value, promotes internal interface decohesion (block and packet martensite boundaries and prior austenite grain boundaries).

Regarding now the $2.25 \mathrm{Cr} 1 \mathrm{MoV} 650$ grade (the less sensible studied grade to hydrogen embrittlement), the hydrogen precharged specimens tested under a frequency of $0.1 \mathrm{~Hz}$ showed a similar failure appearence to that observed in the uncharged specimen, being also crack propagation rates very close in both cases (Fig. 6c). 


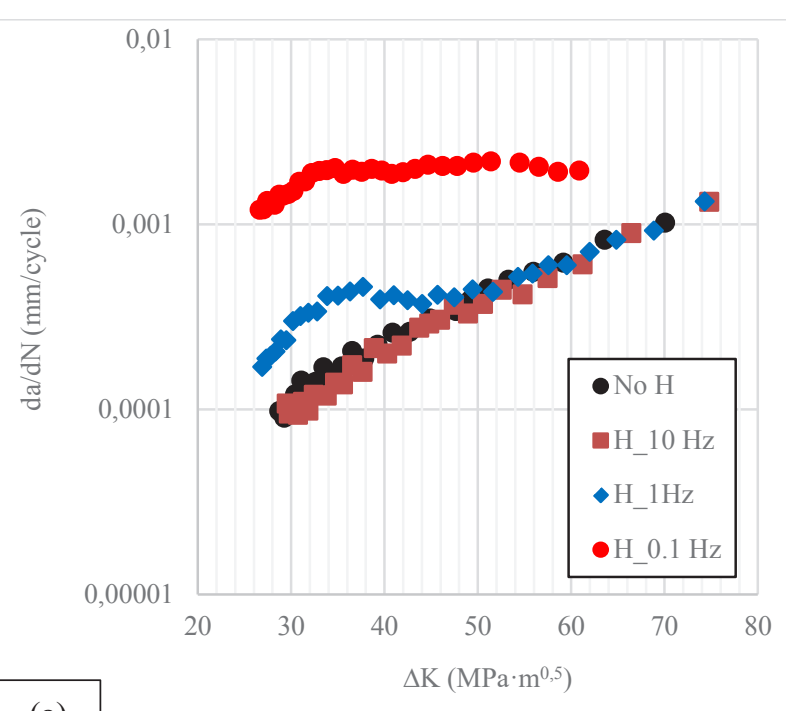

(a)
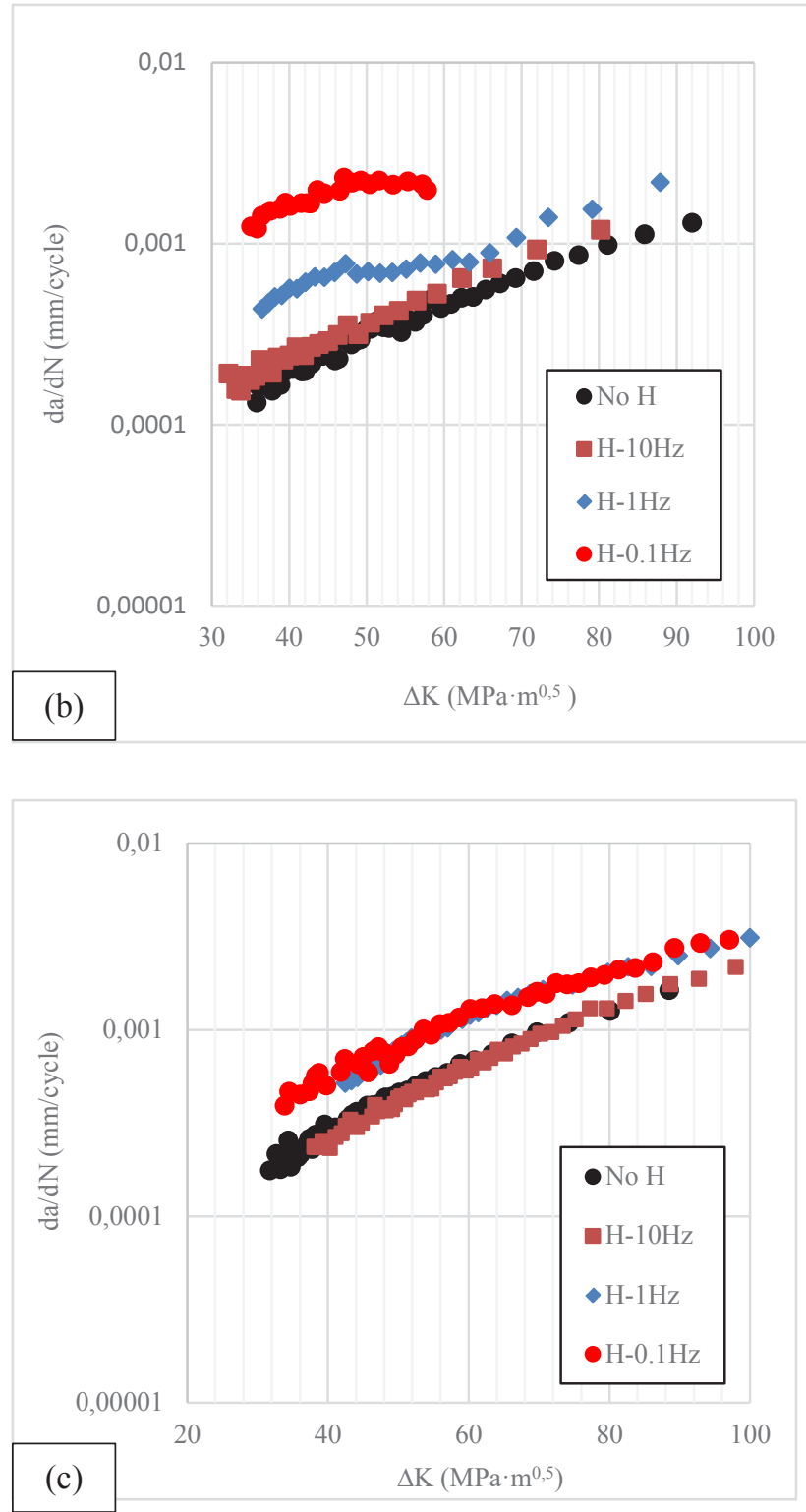

Fig. 6. Fatigue crack growth rates versus $\Delta \mathrm{K}$ curves CrMo_690 (a), CrMo_600 (b) and CrMoV_650 (c).

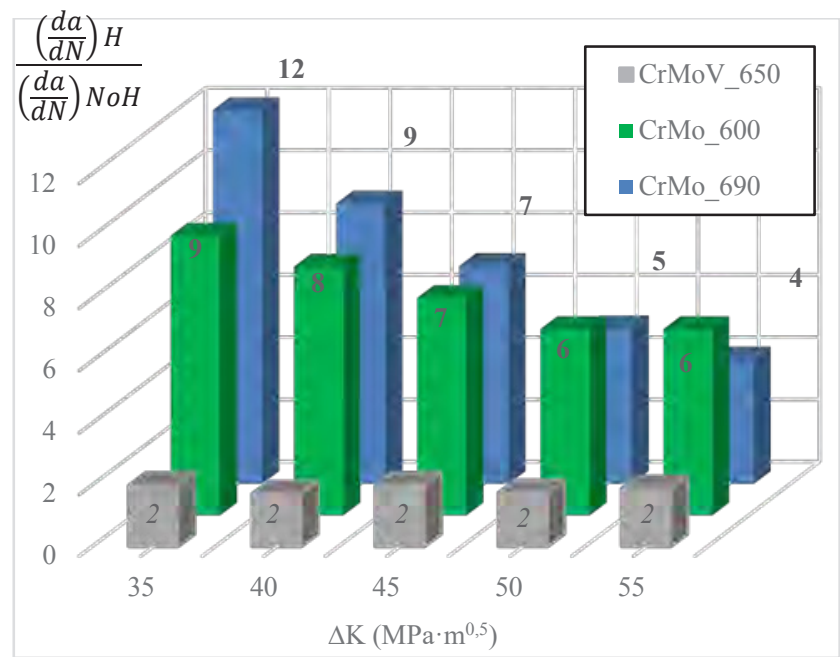

Fig. 7. Fatigue crack growth acceleration factor due to internal hydrogen. $\mathrm{R}=0.1$ and $\mathrm{f}=0.1 \mathrm{~Hz}$.
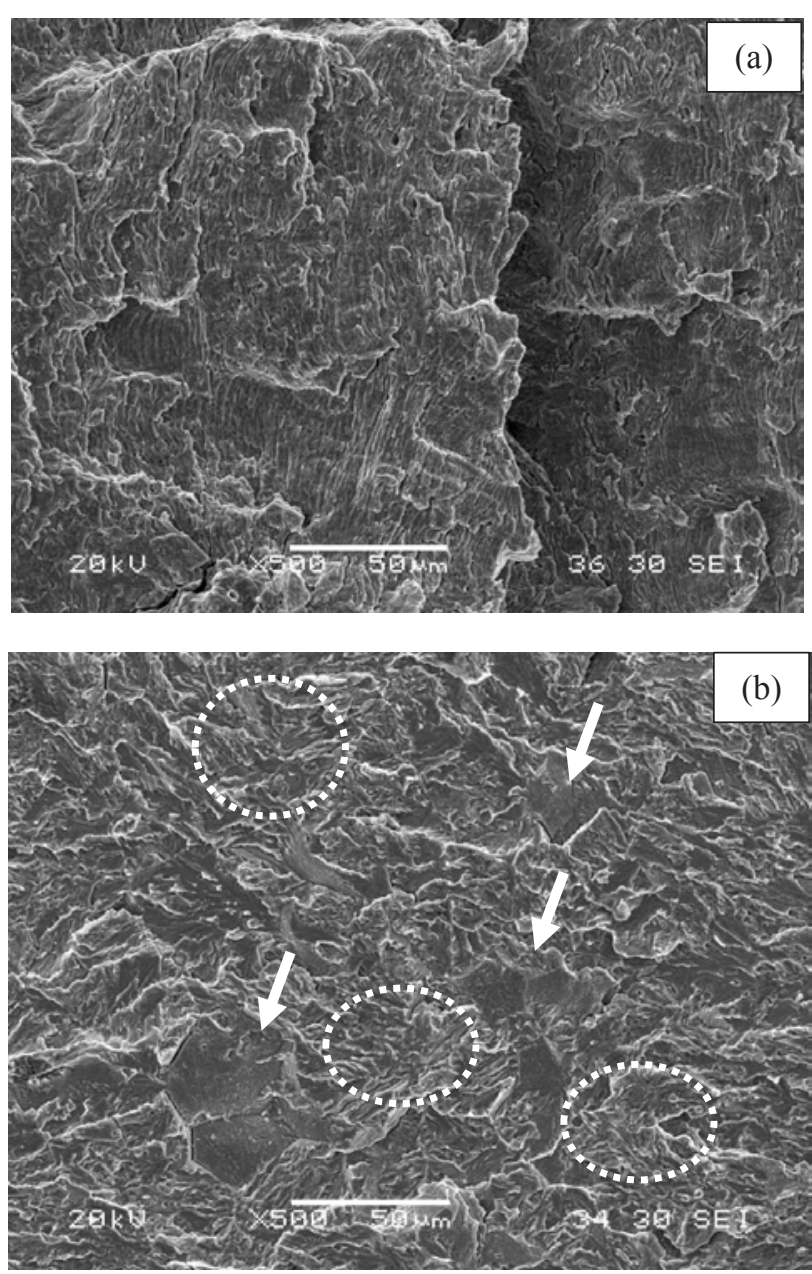

Fig. 8. CrMo $690(\mathrm{R}=0.1)$.

$\mathrm{f}=10 \mathrm{~Hz}$, uncharged, $\Delta \mathrm{K} \approx 40 \mathrm{MPa} \cdot \sqrt{\mathrm{m}}$ (a).

$\mathrm{f}=0.1 \mathrm{~Hz}$, hydrogen pre-charged, $\Delta \mathrm{K} \approx 40 \mathrm{MPa} \cdot \sqrt{\mathrm{m}}$ (b).

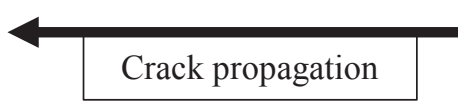

This steel grade (V-added steel) did not exhibit any trace of intergranular or PRHIC fractures. The most remarkable difference between the uncharged and precharged specimen was the presence of secondary 
cracks due to the presence of hydrogen (white arrows, Fig.9.b)
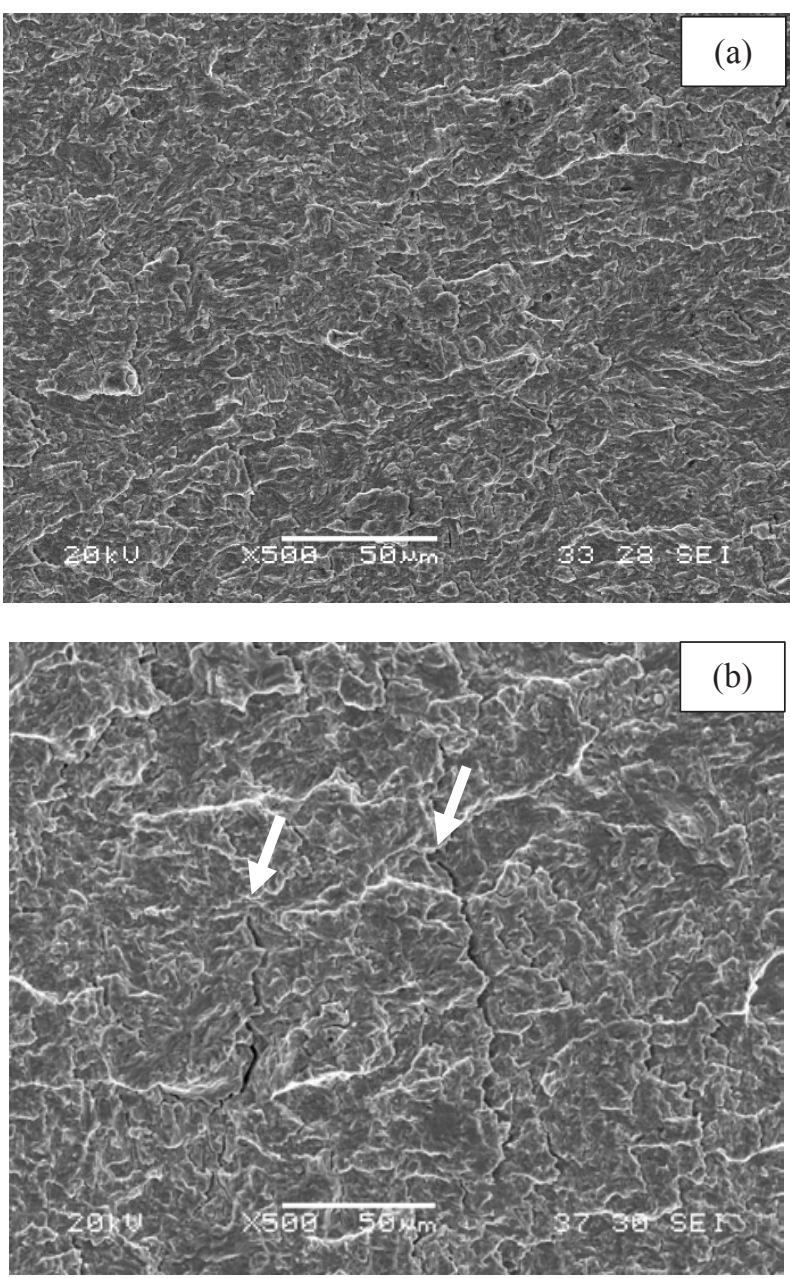

Fig. 9. $\mathrm{CrMoV} 650(\mathrm{R}=0.1)$. $\mathrm{f}=10 \mathrm{~Hz}$, uncharged, $\Delta \overline{\mathrm{K}} \approx 40 \mathrm{MPa} \cdot \sqrt{\mathrm{m}}$ (a).

$\mathrm{f}=0.1 \mathrm{~Hz}$, hydrogen pre-charged, $\Delta \mathrm{K} \approx 40 \mathrm{MPa} \cdot \sqrt{\mathrm{m}}$ (b).

$$
\text { Crack propagation }
$$

\section{Discussion}

In order to discuss the fatigue results obtained in this work, it is necessary to remember that when a mechanical load is applied on a hydrogen precharged CT specimen, hydrogen located in the crack tip surroundings will diffuse up to the zone of maximum triaxiality (maximum hydrostatic stress) existing just ahead of the crack tip, where it will accumulate, giving rise to the embrittlement phenomenon (hydrogen enhanced descohesion, HEDE, and/or hydrogen enhanced localized plasticity, HELP mechanisms). In this way, the influence of the test frequency on the fatigue crack growth rate will depend on the time that hydrogen has to move in each fatigue load cycle to attain a critical concentration in the aforementioned process region (see Figure 10).

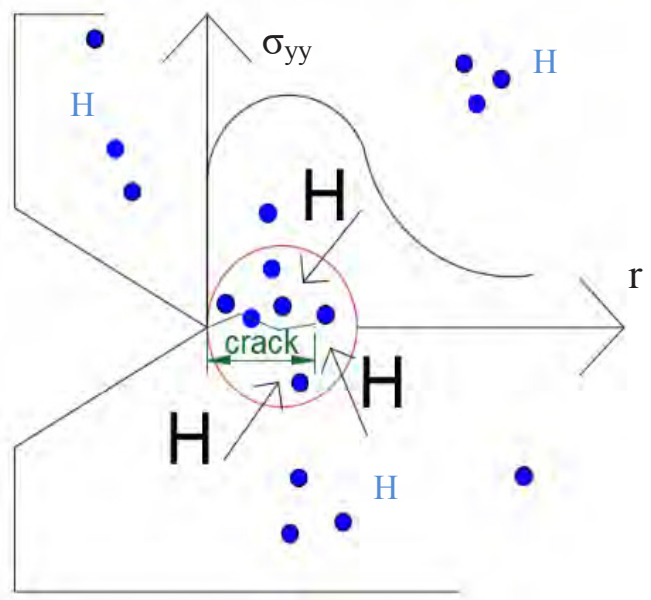

Fig. 10. Crack extension in the process zone ahead of an opened crack tip.

So, the hydrogen crack growth acceleration factor observed under low fatigue frequencies, lower than 10 $\mathrm{Hz}$ (see figures 6 and 7) might be explained from the effective diffusion distance, $x$, available for hydrogen movement along the fatigue cycle, that can be estimated from Fick's second law, equation 3.

$$
x=\sqrt{D t}
$$

(equation 3)

D being the apparent hydrogen diffusion coefficient in the steel and $t$, the time available in each fatigue cycle $(t$ $=1 / \mathrm{f}$ ). Table 6 shows the hydrogen effective diffusion distances calculated for each steel grade as a function of the applied test frequency.

\begin{tabular}{|c|c|c|c|c|}
\hline \multirow[b]{2}{*}{ Acero } & \multirow[b]{2}{*}{$\begin{array}{c}\mathrm{D}_{\mathrm{app}} \\
\left(\mathrm{m}^{2} / \mathrm{s}\right)\end{array}$} & $10 \mathrm{~Hz}$ & $1 \mathrm{~Hz}$ & $0.1 \mathrm{~Hz}$ \\
\hline & & $\begin{array}{c}0.1 \\
\text { s/cycle }\end{array}$ & $\begin{array}{c}1 \\
\text { s/cycle }\end{array}$ & $\begin{array}{c}10 \\
\text { s/cycle }\end{array}$ \\
\hline CrMo_690 & $2.4 \cdot 10^{-9}$ & 15 & 49 & 155 \\
\hline $\mathrm{CrMo} 600$ & $8 \cdot 10^{-10}$ & 9 & 28 & 89 \\
\hline $\mathrm{CrMoV} 650$ & $810^{-11}$ & 3 & 9 & 28 \\
\hline
\end{tabular}

Table 6. Effective diffusion distance $(\mu \mathrm{m})$.

In this way, when the test frequency is high $(10 \mathrm{~Hz})$, fatigue cycle load time is low, and consequently, the hydrogen diffusion distances are also very low. Hence, hydrogen accumulation in the crack tip region is barely significant and the fatigue crack growth rate doesn't differ from the one determined without hydrogen in air (see Figure 6). Nevertheless, when the test frequency decreases, hydrogen effective diffusion distances increase significantly, reaching values, which allow important hydrogen accumulation in the crack tip region. In this case, hydrogen diffusion would be coupled with the crack growth rate, hydrogen atoms will diffuse in and out of the process zone in each one of the fatigue cycles, enabling the existance of the so-called embrittled process zone due to hydrogen accumulation. This fact would explain the increase in the crack growth rate observed in the CrMo steels cycled at low frequencies. By the contrary, hydrogen effect was notably lower in the $\mathrm{CrMoV}$ steel. It is worth noting that the effective 
diffusion distances in the $\mathrm{V}$-added steel tested at $0.1 \mathrm{~Hz}$ were nearly similar to that observed in the CrMo steel tempered at $690^{\circ} \mathrm{C}$ and tested at $10 \mathrm{~Hz}$. As mentioned above, $\mathrm{V}$-added steel has the capacity to strongly retain hydrogen due to the existance of submicrometric vanadium carbides, reducing the apparent diffusion coefficient and, consequently the effective disffusion distances, even under quite low frequencies.

It is also important to note that from a certain $\Delta \mathrm{K}$ value (or a certain crack propagation rate, da/dN), a kind of 'plateau ' in the crack propagation rate was detected. A plateau like this one is typically referred in the scientific literature when a phenomenon of stress corrosion cracking (SCC) or hydrogen assisted cracking (HAC) is present [9]. Under these circumstances if the applied stress intensity factor in the fatigue cycle exceeds a threshold value, $\mathrm{K}_{\mathrm{ISCC}}$, the crack extends at a constant growth rate independent of the applied $\Delta \mathrm{K}$.

Another explanation for this phenomenon could be based on the progressive loss of hydrogen during the fatigue test. For example, based on the desorption curve present in Figure 3, the fatigue CT specimen of CrMo_690 steel grade after 10 hours testing at $1 \mathrm{~Hz}$, would have already lost all its diffusible hydrogen and it should be expected that the fatigue crack growth rate curve would superpose with the one determined without hydrogen (Figure 6a). Nevertheless, when the fatigue test frequency decreased to $0.1 \mathrm{~Hz}$, significant diffusible hydrogen still remains in the fatigue specimen at the end of the fatigue test and, consequently, fatigue crack growth rate is still higher than the crack propagation rate measured in the uncharged specimen (without hydrogen). Finally, the hydrogen effect in the crack growth rate of the CrMoV steel grade was always barely important, as hydrogen diffusion coeficient and effective diffusion distances were both very low.

\section{Conclusions}

The presence of internal hydrogen causes an increase of the crack propagation rate in the CrMo steel grades and this effect is larger as the test frequency applied in the fatigue test is reduced. This behaviour can be explained assuming that hydrogen embrittlement is controlled by the diffusion of hydrogen atoms toward the process zone existing in the the advancing crack tip. As frequency decreases, hydrogen diffusion distances in the fatigue cycle increase and hydrogen concentration in the process zone can attain a critical value for the decohesion of intenal boundaries, martensite blocks and packets or prior austenitic grains.

The CrMoV steel has a uniform dispersion of submicrometric vanadium carbides which act as strong traps for hydrogen, significantly reducing the apparent diffusion coefficient and the effective diffusion distances in the fatigue cycle. The fatigue behaviour of this steel grade in presence of internal hydrogen was much improved and the effect of frequency was in this case nearly negligeable.
Finally, hydrogen pre-charged CT specimens gradually lose hydrogen during the fatigue test. Consequently, it is important to control the total duration of the test, in order to avoid excessive hydrogen loss.

The authors would like to thank the Spanish Ministry of Economy and Competitivity for the support received for the development of the research project MAT2014-58738-C3 (SAFEHIDROSTEEL) and L. Borja Peral the financial aid given by FEDER and the Asturias government, through the project FC-15-GRUPIN14-001.

\section{References}

[1] Gangloff R.P., Sommerday B.P. Edit., Gaseous hydrogen embrittlement of materials in energy technologies, Woodhead Publishing, (2012).

[2] Murakami Y., Matsuoka S., Effect of hydrogen on fatigue crack growth of metals, Engineering Fracture Mechanics, 77 (2010) 1926-1940.

[3] Murakami Y., Effects of hydrogen in metal fatigue, Proceedings of the international hydrogen energy development forum, Fukuoka, Japan (2007) 96-105.

[4] ASTM E647, Standard test method for measurement of fatigue crack growth rates, Annual Book of ASTM Standards, Vol. 03.01, (2015).

[5] S. Pillot, L. Coudreuse, Hydrogen-induced disbonding and embrittlement of steels used in petrochemical refining, Woodhead Pub. Ltd., (2012).

[6] Lee T., "Effects of Vanadium Carbides on Hydrogen Embrittlement of Tempered Martensitic Steel", Met. Mater. Int., Vol. 22, No 3 (2016), pp. 364-372.

[7] A.Sciuccati et al, "Effect of hydrogen and low temperature on fatigue crack growth of pipelines steels" , Engineering Fracture Mechanics (2013) 10-25.

[8] Nibur K.A., "The Relationship Between Crack-tip Strain and Subcritical Cranking Tresholds for Steels in High-Pressure Hydrogen Gas", The Minerals, Metals \& Materials Society and ASM International, (2012).

[9] R.H. Jones, Edit., Stress-corrosion cracking. Materials performance and evaluation, ASM International, (2017). 